\title{
RANCANG BANGUN SISTEM INFORMASI GEOGRAFIS (SIG) PRAKTEK KERJA LAPANGAN (PKL) BERBASIS WEB (STUDI KASUS UNIVERSITAS DHARMAWANGSA)
}

\author{
Ega Evinda Putri', Randika Farike Bania ${ }^{2}$ \\ 1,2. Universitas Dharmawangsa \\ Jl. K.L Yos Sudaro No.224, Medan 20115 \\ e-mail : ega@dharmawangsa.ac.id
}

\begin{abstract}
ABSTRAK
Sistem Informasi Geografis (SIG) merupakan suatu sistem informasi yang berbasiskan komputer untuk membangun, menyimpan, mengelola dan menganalisis, serta memanggil dan menampilkan informasi bereferensi geografis seperti data di identifikasi berdasarkan lokasinya dalam database. PKL adalah salah satu matakuliah wajib yang ada pada beberapa Prodi untuk diikuti oleh setiap mahasiswa dalam kurun waktu yang ditentukan untuk memenuhi persyaratan kelulusan. SIG memberikan kemudahan kepada Prodi dalam mendistribusikan mahasiswanya untuk melaksanakan PKL baik ke Instansi Pemerintahan maupun Swasta. Metode penelitian ini menggunakan tahap-tahap didalam Siklus Pengembang Sistem atau System Development Life Cycle ( SDLC ), mulai dari Tahap awal penelitian, analisa sistem, pengumpulan data, desain sistem, pengujian sistem dan pemeliharaan sistem. SIG PKL dapat digunakan dalam melakukan pengolahan data mahasiswa yang melakukan PKL.. Mahasiswa dapat mengakses informasi mengenai detail dan gambaran tempat PKL, peta atau lokasi secara online dan Panduan Praktek Kerja Lapangan.
\end{abstract}

Kata kunci: SIG, Sistem Informasi, Spasial, Pemetaan, PKL

\begin{abstract}
Geographic information system (GIS) is a computer-based information system that builds, stores, manages and analyzes, and calls and displays geographically undifferentiated information such as data identified based on its location in a database. PKL is one of the compulsory courses in some study programs to be followed by each student within the specified period to meet the graduation requirements. SIG provides convenience to Prodi in distributing its students to carry out street vendors both to government and private agencies. This research method uses the stages in the System Development Life Cycle (SDLC), starting from the initial stages of research, system analysis, data collection, system design, system testing and system maintenance. SIG PKL can be used in processing student data that performs street vendors. Students can access information about details and descriptions of street vendors, maps or online locations, procedures, guidelines and procedures for the assessment of street vendors.
\end{abstract}

Keywolrds: SIG, Information System, Spatial, Mapping, PKL

\section{PENDAHULUAN}

Dunia Pendidikan di Indonesia khususnya Perguruan Tinggi Negeri maupun Perguruan Tinggi Swasta memiliki matakuliah Praktek Kerja Lapangan (PKL), terutama di Universitas Dharmawangsa (Undhar) Medan pada Fakultas Teknik dan Ilmu Komputer (FTIK). PKL adalah salah satu matakuliah wajib yang ada pada beberapa Prodi untuk diikuti oleh setiap mahasiswa dalam kurun waktu yang ditentukan untuk memenuhi persyaratan kelulusan. Pelaksanaan PKL bertujuan untuk melatih mahasiswa agar mampu beradaptasi dengan dunia kerja serta memberikan pengalaman kepada mahasiswa tentang sistem kerja di instansi pemerintah ataupun swasta agar mereka 
IN F O R M A I I A

Jurnal Informatika, Manajemen dan Komputer, Vol. 13, No. 2, Desember 2021

eISSN : 2580-3042

pISSN : 1979-0694

memahami bagaimana sistem dunia kerja yang akan di hadapinya kedepan. Dalam melaksanakan PKL mahasiswa dituntut untuk memenuhi syarat-syarat yang sudah ditentukan oleh Fakultas Teknik dan Ilmu Komputer, diantaranya dalam menyajikan seluruh kebutuhan data dan informasi agar dapat mengurangi kerancuan dalam proses pengajuan PKL, serta dosen yang bertanggung jawab tidak kesulitan dalam menentukan lokasi tempat mahasiswa akan melaksanakan PKL. Maka FTIK membutuhkan sebuah Sistem Informasi, agar dapat memudahkan dalam melakukan kegiatan PKL Mahasiswa. Sistem Informasi merupakan suatu sistem didalam suatu organisasi untuk memenuhi sebuah kebutuhan pengolahan data sebagai pendukung fungsi operasional organisasi serta dapat memberikan informasi kepada pihak luar tenrtentu sesuai laporan-laporan yang dibutuhkan.

Sebuah Sistem Informasi yang berbasis komputer merupakan satu set perangkat keras (Harware), Perangkat Lunak (Software) mempunyai sebuah database, adanya jaringan serta orang (Brainware) untuk menjalankan sistem informasi tersebut yang dikonfigurasi untuk mengumpulkan, menyimpan, memanipulasi serta mengolah data menjadi sebuah informasi.

Sistem Informasi yang dibutuhkan yaitu Sistem Informasi Geografis (SIG), dengan dibangunnya Sistem Informasi Geografis memberikan kemudahan kepada para pengguna atau para pengambil keputusan untuk menentukan kebijaksanaan yang akan diambil, khususnya yang berkaitan dengan aspek keruangan (spasial) dan menjadi produk yang memiliki nilai tambah bagi penggunaanya. Pada saat sekarang perkembangan SIG sangat pesat, SIG digunakan sebagai informasi yang berasal dari pengolahan sejumlah data geografis atau data yang berhubungan dengan tata letak sebuah objek di muka bumi. SIG adalah sebuah sistem informasi yang berbasiskan komputer didalam menyimpan, menganalisis dan mengelola serta memanggil data yang bersifat geografis dimana sistem ini berkembang pesat didalam lima tahun terkahir.

Berdasarkan uraian diatas, peneliti tertarik membangun sebuah sistem yang dapat memudahkan Fakultas Teknik dan Ilmu Komputer Universitas Dharmawangsa dalam melakukan kegiatan PKL bagi mahasiswa. Sistem tersebut dapat memastikan dimana mahasiswa akan melakukan PKL dengan lokasi yang detail. PKL dijadikan sebagai bentuk

peningkatan wawasan mahasiswa didalam dunia kerja serta dapat menerapkan ilmu yang didapat untuk persoalan yang akan dihadapi kedepannya. Pemanfaatan SIG akan memudahkan dalam mendistribusikan mahasiswa untuk melaksanakan PKL baik ke Instansi Pemerintahan maupun Swasta. Instansi tersebut berupa Kantor Pemerintahan, BUMN, Perusahaan Swasta, Institusi Pendidikan, Perbankan dan Intansi lainnya.

Penelitian ini diharapkan mampu memudahkan pengguna dalam mengakses lokasilokasi yang tepat untuk dijadikan sebagai tempat PKL Mahasiswa. Dengan adanya SIG PKL ini, maka Fakultas mudah melakukan pengolahan data mahasiswa yang melakukan PKL serta dapat mengelola data dan informasi yang dapat diakses oleh mahasiswa. Mahasiswa dapat mengakses informasi mengenai detail dan gambaran tempat PKL, peta atau lokasi secara online, Tata Cara, Panduan dan Prosedur Penilaian PKL.

\section{METODOLOGI PENELITIAN}

Metodologi penelitian meliputi objek penelitian, unit analisis, dan kerangka kerja (Framework).

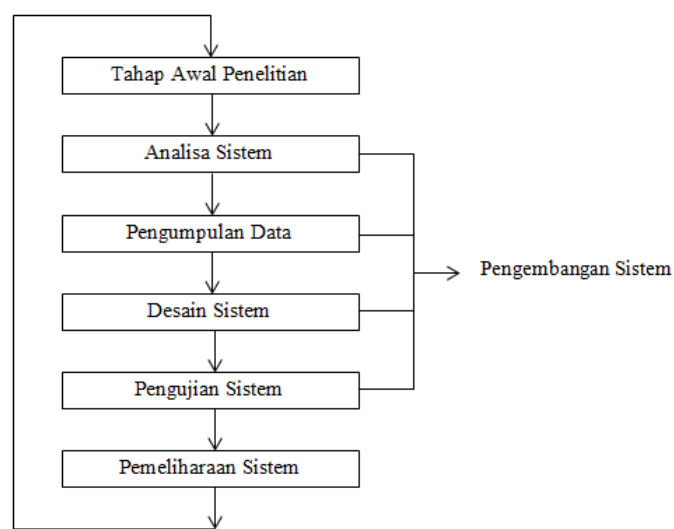

Gambar 1. Kerangka Kerja Penelitian

a. Tahap Awal Penelitian

Pada tahap ini Peneliti melakukan survey dan interview untuk mengidentifikasi masalah serta merumuskan permasalahan dalam proses pelaksanaan PKL.

b. Analisa Sistem

Berikut ini merupakan Analisa yang dibutuhkan sistem nantinya dalam proses pengembangan. Dengan menganalisa masalah yang telah dilakukan, maka diharapkan pengguna dapat memahami dengan baik kebutuhan-kebutuhan yang 
I N F O R M A I I A

Jurnal Informatika, Manajemen dan Komputer, Vol. 13, No. 2, Desember 2021

eISSN : 2580-3042

pISSN : 1979-0694

diperlukan dalam pembangunan sistem informasi geografis.

c. Pengumpulan Data

Dalam hal ini peneliti menggunakan cara pengambilan informasi data PKL pada setiap Fakultas Teknik dan Ilmu Komputer Universitas Dharmawangsa. Pengambilan data melalui google map untuk mengetahui titik koordinat dan informasi lainnya.

d. Desain Sistem

Desain sistem pada penelitian ini menggunakan UML (Unified Modelling Language) diantaranya Use Case Diagram, Class Diagram dan Activity Diagram.

e. Pengujian Sistem

Pengujian sistem ini akan dilakukan uji coba secara langsung oleh Fakultas Teknik dan Ilmu Komputer Universitas Dharmawangsa.

f. Pemeliharaan sistem

Pemeliharaan sistem ini sangat dibutuhkan, karena diperlukan sebuah pengembangan, sistem yang dibuat tidak selamanya baik, ketka dijalankan mungkin akan terjadi error kecil yang tidak terjadi sebelumnya, serta bisa manambahkan fitur-fitur yang belum ada pada sistem sebelumnya.

\section{HASIL DAN PEMBAHASAN}

a. Analisa dan Desain Sistem

Sistem Informasi Geografis dirancang untuk memudahkan Mahasiswa dalam mengakses media informasi, secara jarak jauh sehingga informasi tersebut dapat dengan cepat diakses oleh Mahasiswa serta pihak-pihak yang terkait. SIG dibangun berbasiskan internet sehingga dapat diakses secara realtime. SIG dikelola oleh seorang admin, yang dapat mengakses dan mengolah data, sedangkan mahasiswa dapat melihat dan mengakses informasi yang diinginkan seperti, detail dan gambaran tempat PKL, peta atau lokasi secara online dan Panduan Praktek Kerja Lapangan.

\section{Use Case Diagram}

Use Case Diagram telah digambarkan akan terdapat 2 aktor yaitu admin dan mahasiswa. Admin melakukan login untuk mengelola peta, data lokasi pkl, menu berita dan menu download untuk melakukan penambahan, pengeditan serta penghapusan data. Mahasiswa dapat melihat detail dan gambaran tempat PKL, peta atau lokasi secara online dan Download Panduan Praktek Kerja Lapangan.
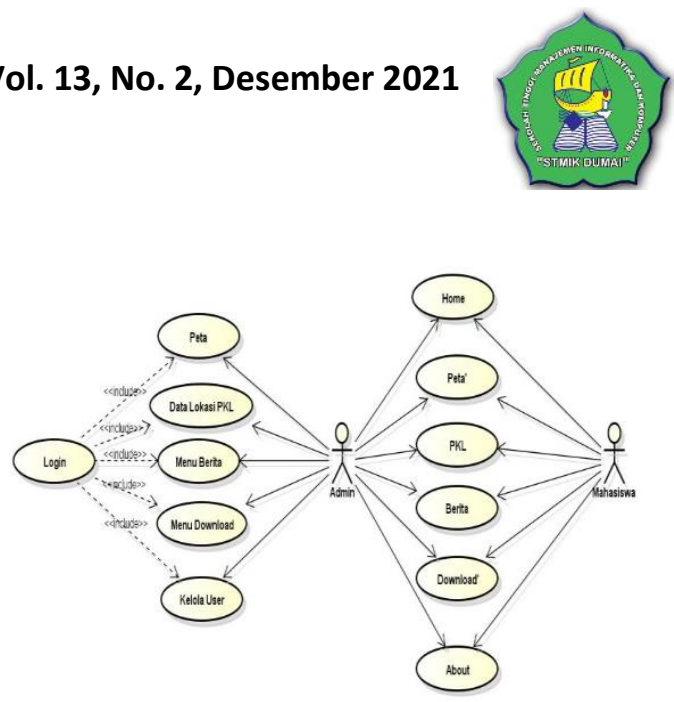

Gambar 1. Use Case Diagram

2. Class Diagram

Terdapat beberapa tabel dan menentukan class SIG yaitu seperti gambar dibawah ini:

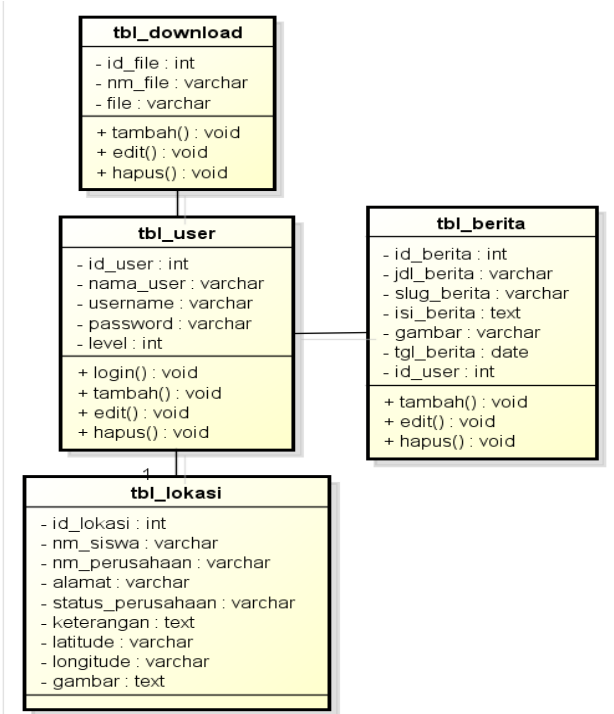

Gambar 2. Class Diagram

3. Activity Diagram

Activity Diagram menggambarkan berbagai alir aktivitas dalam sistem yang sedang dirancang, mulai dari awal aktivitas sampai terakhir, terbagi atas 2 yaitu Admin dan Mahasiswa. Activity dapat dilihat pada gambar dibawah ini: 
IN F O R M A I I A

Jurnal Informatika, Manajemen dan Komputer, Vol. 13, No. 2, Desember 2021

eISSN : 2580-3042

pISSN : 1979-0694

a. Activity Diagram Admin

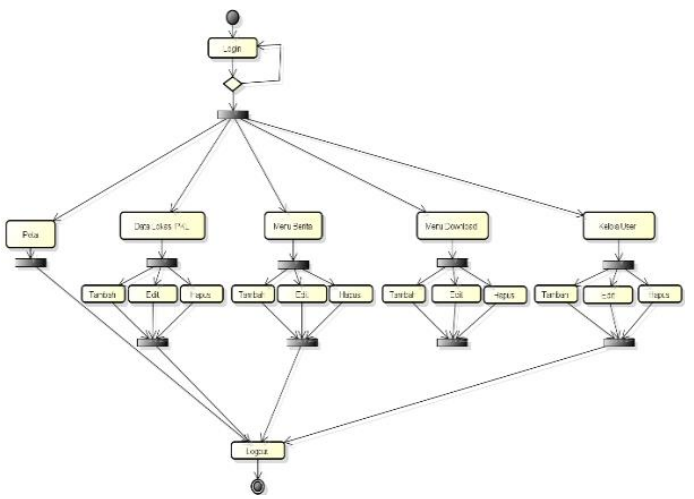

Gambar 3. Activity Diagram Admin

b. Activity Diagram Mahasiswa

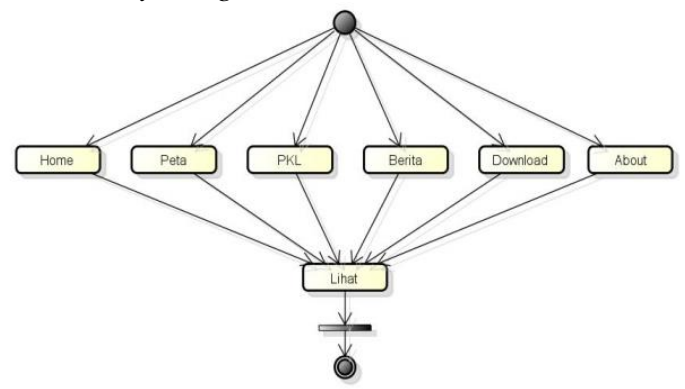

Gambar 4. Activity Diagram Mahasiswa

\section{b. Pengujian Sistem}

Pengujian Sistem bertujuan untuk melihat apakah sistem yang dirancang telah sesuai dengan yang diinginkan. Pada gambar dibawah ini akan dijelaskan bagaimana cara program dieksekusi, berdasarkan fungsi dan menu nya masing-masing.

1. Tampilan Menu Utama

Menu utama merupakan tampilan awal pada saat program dijalankan. Pada tampilan awal ini terdapat beberapa menu yang dapat diakses oleh mahasiswa. Seperti gambar dibawah ini:

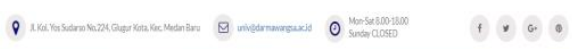

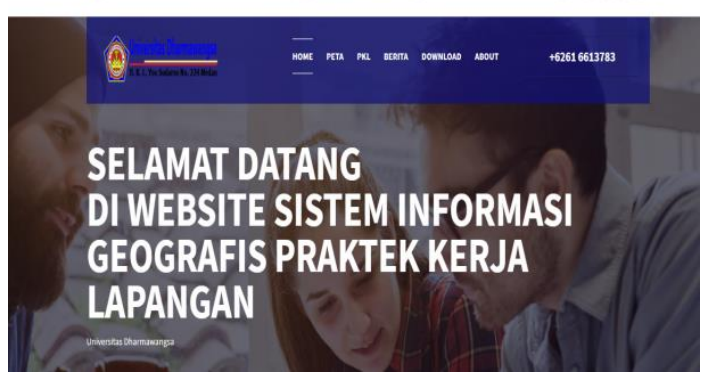

Gambar 5. Tampilan Menu Utama

2. Tampilan Menu PKL

Menu PKL menampilkan data-data mahasiswa yang melakukan PKL yaitu Nama Perusahaan, Alamat, Status Perusahaan, Nama Mahasiswa serta Keterangan Kegiatan. Dapat dilihat pada gambar dibawah ini:
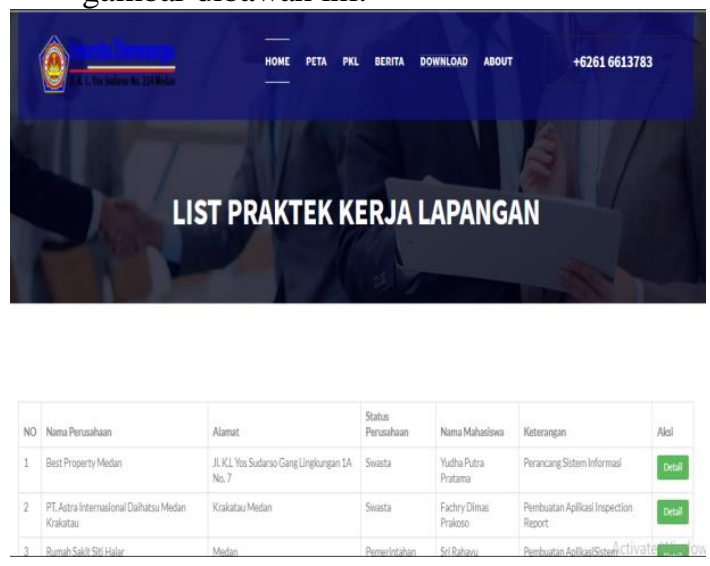

Gambar 6. Tampilan Menu PKL

3. Tampilan Detail Lokasi PKL

Pada halaman Detail PKL menampilkan secara detail lokasi PKL, seperti gambar dibawah ini:

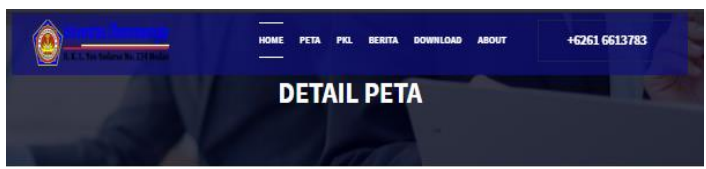

DETAIL LOKASI

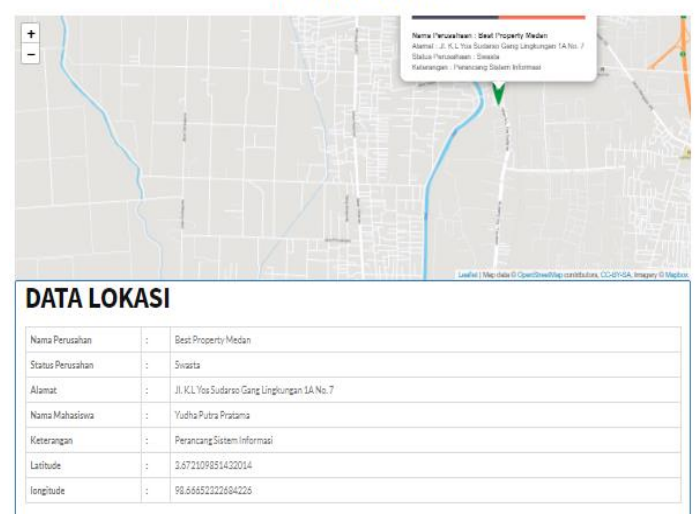

Gambar 7. Detail PKL

4. Tampilan Menu Berita

Pada menu Berita menampilkan informasi terbaru seputar Universitas Dharmawangsa dan Informasi Praktek Kerja Lapangan. 
IN F ORM A T I K

Jurnal Informatika, Manajemen dan Komputer, Vol. 13, No. 2, Desember 2021

eISSN : 2580-3042

pISSN : 1979-0694
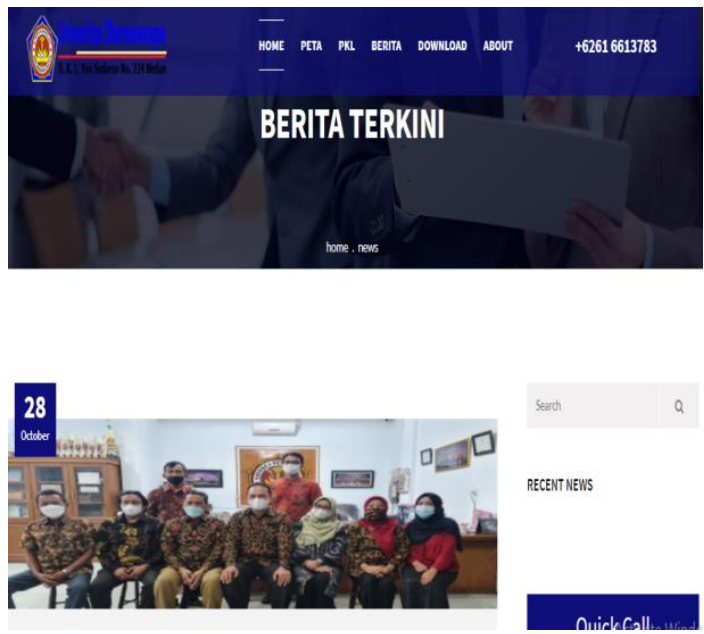

Gambar 8. Tampilan Menu Berita

5. Tampilan Menu Download

Pada tampilan menu download mahasiswa dapat mendownload secara langsung tentang jadwal PKL dan Buku Panduan PKL. Dapat dilihat pada gambar dibawah ini:
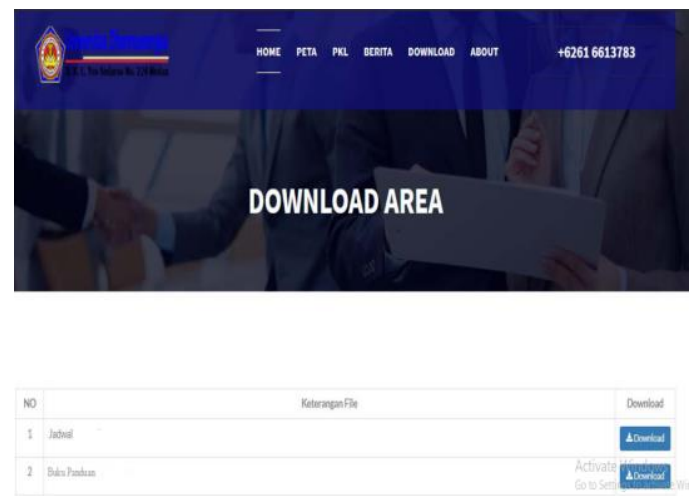

Gambar 9. Tampilan Menu Download

6. Tampilan Menu Login

Menu Login merupakan tempat pengolahan data oleh Admin.

\section{GIS PRAKTEK KERJA LAPANGAN : Login}

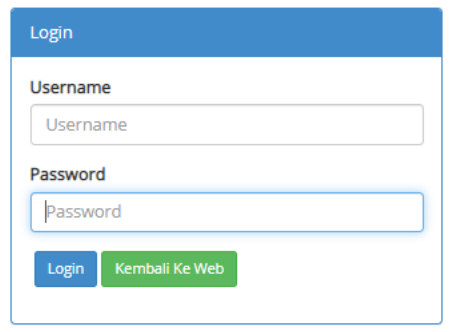

Gambar 10. Tampilan Menu Login
7. Tampilan Halaman Admin

Pada halaman admin terdapat menu-menu untuk pengolahan data PKL yang terdiri dari Peta, Data Lokasi PKL, Menu Berita, Menu Download dan Menu Kelola User.
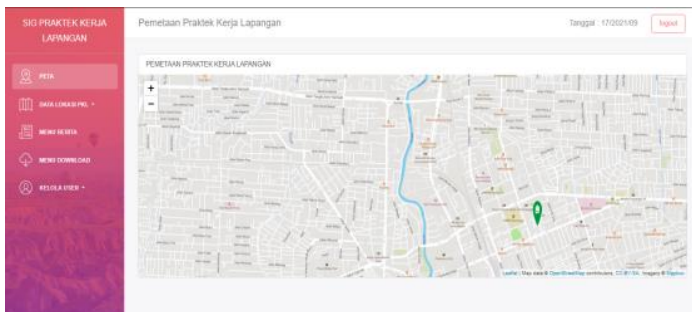

Gambar 11. Tampilan Halaman Admin

\section{KESIMPULAN}

Berdasarkan penelitian yang dilakukan terhadap rancang bangun Sistem Informasi Geografis dapat ditarik beberapa kesimpulan yaitu sebagai berikut:

1. Data Praktek Kerja Lapangan (PKL) Mahasiswa yang berjalan saat ini hanya dicatat secara manual, dengan adanya SIG Data PKL sehingga dapat memudahkan Mahasiswa dalam mengetahui detail PKL yang akan dilaksanakan.

2. Sistem Informasi Geografis (SIG) dapat memudahkan mahasiswa mengetahui detail lokasi PKL secara rinci dan jelas.

3. SIG membantu mahasiswa untuk menuju lokasi PKL dengan menggunakan detail lokasi Peta yang ada pada aplikasi.

4. SIG memberikan kemudahan kepada mahasiswa dalam mengetahui jadwal pelaksanaan PKL serta dengan mudah mendapatkan buku panduan PKL walaupun secara jarak jauh.

\section{REFERENSI}

Antares, J. (2020). Rancangan Sistem Informasi Kependudukan Berbasis Web Di Kantor Camat Medan Deli. Djtechno: Jurnal Teknologi Informasi, 1(2), 46-51.

Bakti, I. R., Bunda, Y. P., \& Utari, C. T. (2021). Rancang Bangun Sistem Informasi Geografis (Sig) Lokasi Praktek Kerja Industri (Prakerin) Smk Methodist Medan Berbasis Web. Rabit: Jurnal Teknologi Dan Sistem Informasi Univrab, 6(1), 1-6.

Darwis, D., Ferico Octaviansyah, A., Sulistiani, 
IN F ORM A I K A

Jurnal Informatika, Manajemen dan Komputer, Vol. 13, No. 2, Desember 2021

eISSN : 2580-3042

pISSN : 1979-0694

H., \& Putra, R. (2020). Aplikasi Sistem Informasi Geografis Pencarian Puskesmas Di Kabupaten Lampung Timur. Jurnal Komputer Dan Informatika, 15(1), 159170.

Khatami, M., Pasya, A. N. K., Putri, E. E., Simon, J., Sos, S., \& Si, M. (2021). Syntax : Syntax : $128-133$.

SIHOTANG, H. T. (2019). Sistem Informasi Pengagendaan Surat Berbasis Web Pada Pengadilan Tinggi Medan. 3(1), 6-9. 